\title{
ABSORÇÃO DE NUTRIENTES E CRESCIMENTO DO ARROZ COM SUPRIMENTO COMBINADO DE AMÔNIO E NITRATO(1)
}

\author{
Marquel Jonas Holzschuh ${ }^{(2)}$, Humberto Bohnen ${ }^{(3)}$, Ibanor Anghinoni ${ }^{(4)}$, Tânia \\ Mara Pizzolato $^{(5)}$, Felipe de Campos Carmona ${ }^{(6)}$ \& Filipe Selau Carlos ${ }^{(7)}$
}

\begin{abstract}
RESUMO
O arroz é classificado como uma planta tolerante ao amônio $\left(\mathrm{NH}_{4}^{+}\right)$devido à predominância desse íon nos solos alagados. Entretanto, nas regiões oxidadas do solo e da rizosfera do arroz pode haver a formação de nitrato $\left(\mathrm{NO}_{3}{ }^{-}\right)$e esta se tornar importante fonte de $\mathrm{N}$ para cultura. Este trabalho foi conduzido com o objetivo de avaliar o efeito de diferentes proporções entre os íons $\mathrm{NH}_{4}{ }^{+}$e $\mathrm{NO}_{3}{ }^{-}$no desenvolvimento do arroz em solução nutritiva. $O$ experimento foi realizado em casa de vegetação no período de janeiro a fevereiro de 2008 , em solução nutritiva com as seguintes proporções entre $\mathrm{NH}_{4}{ }^{+}$e $\mathrm{NO}_{3}{ }^{-}:$100:0, 75:25, 50:50, 25:75 e 0:100 na concentração de $5,0 \mathrm{mmol} \mathrm{L}^{-1}$ de $\mathrm{N}$. Foi cultivado o genótipo IRGA 417 e avaliado o rendimento de biomassa, os teores de $\mathrm{N}, \mathrm{K}$, Ca e Mg na biomassa e na seiva do xilema. Houve toxidez por $\mathrm{NH}_{4}{ }^{+}$nas proporções de 100:0 e 75:25 e por $\mathrm{NO}_{3}{ }^{-}$nas proporções de 25:75 e 0:100. Na proporção de 50:50 as plantas se desenvolveram normalmente. $\mathrm{O}$ suprimento combinado de $\mathrm{NH}_{4}{ }^{+} \mathrm{e} \mathrm{NO}_{3}{ }^{-}$aumentou a produção de biomassa em relação ao $\mathrm{NH}_{4}{ }^{+}$e ao $\mathrm{NO}_{3}{ }^{-}$supridos isoladamente. $\mathrm{O} \mathrm{NH}_{4}{ }^{+}$na solução reduziu os teores de Ca e Mg na biomassa, porém não influenciou o teor de $\mathrm{N}$ e o de $\mathrm{K}$. Já na seiva do xilema houve redução nos teores de $\mathrm{K}$, Ca e Mg, indicando que o $\mathrm{NH}_{4}{ }^{+}$influenciou na absorção desses cátions. A quantidade total absorvida de $\mathrm{N}, \mathrm{K}$, $\mathrm{Mg}$ e Ca foi maior com o suprimento combinado de $\mathrm{NH}_{4}{ }^{+}$e $\mathrm{NO}_{3}{ }^{-}$, indicando que, além de promover melhor desenvolvimento das plantas de arroz, aumenta a eficiência de absorção de nutrientes em relação ao suprimento isolado das duas formas de $\mathrm{N}$.
\end{abstract}

Termos de indexação: nitrogênio, toxidez, Oryza sativa L., nitrificação.

\footnotetext{
(1) Trabalho financiado pelo Instituto Riograndense do Arroz (IRGA), Av. Bonifácio Carvalho Bernardes, 1494, CEP 94930-030

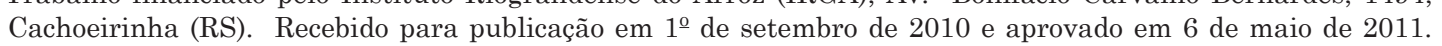

(2) Doutor em Ciência do Solo, Universidade Federal do Rio Grande do Sul - UFRGS. Av. Bento Gonçalves 9500, CEP 91501-970 Porto Alegre (RS). Bolsista CAPES. E-mail: marquelrs@yahoo.com.br

(3) Consultor técnico do Instituto Rio Grandense do Arroz - IRGA. Cachoeirinha (RS). E-mail: humbertobohnen@uol.com.br

(4) Professor do Departamento de Solos, UFRGS. Bolsista CNPq. E-mail: ibanghi@ufrgs.br

(5) Professora do Departamento de Química, UFRGS. Bolsista CNPq. E-mail: taniamar@iq.ufrgs.br

(6) Graduando em Agronomia, UFRGS. Bolsista CNPq. E-mail: filipeselaucarlos@hotmail.com

(7) Doutor em Ciência do Solo, UFRGS. Bolsista CAPES. E-mail: felipecamposcarmona@hotmail.com
} 


\title{
SUMMARY: NUTRIENT ABSORPTION AND RICE GROWTH UNDER AMMONIUM AND NITRATE COMBINED SUPPLY
}

\begin{abstract}
Rice is classified as an ammonium $\left(\mathrm{NH}_{4}^{+}\right)$-tolerant plant due the predominance of this ion in flooded soils. However, in the oxygenated zones of flooded soil and in the rice rhizosphere, nitrate $\left(\mathrm{NO}_{3}{ }^{-}\right)$can be formed and become an important nitrogen $(\mathrm{N})$ source for the crop. This experiment was carried out to evaluate the effect of different ammonium:nitrate proportions on rice development in nutrient solution. The experiment was carried out in a greenhouse, from January until February 2008 in a nutrient solution with the following $\mathrm{NH}_{4}^{+}: \mathrm{NO}_{3}^{-}$proportions: 100:0, 75:25; 50:50; 25:75 and 0:100, at $5.0 \mathrm{mmol} \mathrm{L}^{-1} \mathrm{~N}$. The genotype IRGA 417 was used and the biomass production, the nitrogen, calcium, magnesium and potassium contents in tissue and xylem sap were evaluated. The presence of ammonium at the proportions 100:0 and 75:25 resulted in plant toxicity, as well as for nitrate at the proportions 25:75 and 0:100. The combined supply of ammonium and nitrate increased biomass production in relation to solely $\mathrm{NH}_{4}^{+}$or $\mathrm{NO}_{3}^{-}$supply. Ammonium in solution affected negatively Ca and $\mathrm{Mg}$, whereas no effect was observed on $N$ or K tissue contents. However, in the xylem sap, both $\mathrm{K}$, Ca and Mg contents were affected by ammonium. The higher total absorbed quantities of $N, K, C a$, and $M g$ and better rice development indicated that the combined supply results in higher nutrient absorption efficiency than solely ammonium or nitrate supply.
\end{abstract}

Index terms: nitrogen, toxicity, Oryza sativa L., nitrification.

\section{INTRODUÇÃO}

As principais fontes de $\mathrm{N}$ nos ambientes agrícolas disponíveis para as plantas são o $\mathrm{NH}_{4}{ }^{+}$e o $\mathrm{NO}_{3}{ }^{-}$, as quais coexistem sob variadas relações e concentrações (Britto \& Kronzucker, 2005), desde a faixa $\mu \mathrm{mol} \mathrm{L}^{-1}$ até $\mathrm{mmol} \mathrm{L}^{-1}$ em várias ordens de magnitude (Marschner, 1995). Nos solos alagados, o ambiente anaeróbio e quimicamente reduzido favorece a formação do íon $\mathrm{NH}_{4}^{+}$(Ponnamperuma, 1972), sendo, por isso, considerada a principal forma absorvida de $\mathrm{N}$ pelo arroz irrigado (Oryza sativa L.) (Wang et al., 1993; Kronzucker et al., 2000). $\mathrm{O} \mathrm{NO}_{3}^{-}$, por sua vez, tem recebido pouca importância como fonte de $\mathrm{N}$ para o arroz irrigado por inundação (Kronzucker et al., 2000; Kirk \& Kronzucker, 2005), principalmente porque a sua disponibilidade é reduzida no solo alagado, por ser rapidamente convertido em formas voláteis $\left(\mathrm{NO}, \mathrm{N}_{2} \mathrm{O}\right.$ e $\mathrm{N}_{2}$ ) nas zonas anaeróbias do solo e perdido para a atmosfera (Ponnamperuma, 1972).

A maior parte de $\mathrm{N}$ disponível no solo alagado está na forma de $\mathrm{NH}_{4}{ }^{+}$, e sua absorção e assimilação bioquímica são favorecidas em relação ao $\mathrm{NO}_{3}{ }^{-}$porque seu estado de oxidação elimina a necessidade de redução química na célula (Howitt \& Udvardi, 2000). Em baixas concentrações $(\mu \mathrm{mol} \mathrm{L}-1)$, o $\mathrm{NH}_{4}{ }^{+}$pode ser uma fonte adequada de $\mathrm{N}$ para as plantas, porém, em maiores concentrações $\left(\mathrm{mmol} \mathrm{L}^{-1}\right)$, pode causar problemas de toxidez, principalmente quando administrado como fonte isolada de $\mathrm{N}$ (Gerendas et al., 1997), podendo, em casos severos, levá-las à morte (Kronzucker et al., 2000; Britto \& Kronzucker, 2002). De acordo com Wang et al. (1993), Kronzucker et al.
(2000, 2001) e Britto \& Kronzucker (2002), a toxidez do $\mathrm{NH}_{4}{ }^{+}$é variável entre espécies de plantas, podendo ser tolerado por algumas, como tem sido atribuído à cultura do arroz. No entanto, mesmo espécies tolerantes podem apresentar sintomas de toxidez, como redução do crescimento, sobretudo quando associado à baixa disponibilidade de outros nutrientes $(\mathrm{K}, \mathrm{Ca} \mathrm{e}$ $\mathrm{Mg}$ ) e, ou, concentrações elevadas de N (Britto \& Kronzucker, 2002). Diferentes mecanismos são propostos para explicar a toxidez por $\mathrm{NH}_{4}{ }^{+}$, os quais possivelmente ocorram simultaneamente nas células, tornando difícil a sua compreensão e elucidação (Britto $\&$ Kronzucker, 2002, 2005). Em condição de lavoura, não tem sido relatada a ocorrência de toxidez por $\mathrm{NH}_{4}{ }^{+}$ na cultura do arroz. Por isso, sugere-se que a planta disponha de mecanismos que a tornem eficiente em se desenvolver num ambiente onde essa forma de $\mathrm{N}$ predomine sem causar efeitos nocivos. Entretanto, estudos indicam que o suprimento combinado de $\mathrm{NH}_{4}{ }^{+}$ e $\mathrm{NO}_{3}{ }^{-}$melhora o aproveitamento do $\mathrm{N}$ fornecido e favorece o desenvolvimento de parte aérea e raízes do arroz, quando comparado ao suprimento isolado das duas fontes (Cox \& Reisenauer, 1973; Duan et al., $2006,2007)$. Incrementos que variam de 40 a $70 \%$ foram obtidos por Cox \& Reisenauer (1973) e Qian et al. (2004), indicando a importância da fonte nítrica para o desenvolvimento satisfatório do arroz.

Uma possibilidade de haver a formação e o fornecimento de $\mathrm{NO}_{3}^{-}$para a planta no solo alagado está associada com a liberação de oxigênio na rizosfera do arroz. $\mathrm{O} \mathrm{O}_{2}$ que é transportado via aerênquima até as raízes é, em parte, liberado na superfície da raiz e na rizosfera (Armstrong, 1971; Colmer, 2003), 
criando condições favoráveis para o desenvolvimento de microrganismos aeróbios - entre eles, os nitrificadores (Kirk, 2001; Li et al., 2006). Essa transformação sugere que esse possa ser um mecanismo responsável por reduzir a quantidade de $\mathrm{NH}_{4}{ }^{+}$absorvido, evitando a toxidez, e, ainda, fornecer as duas formas de $\mathrm{N}$ para a planta (Kronzucker et al., 2000, Briones Jr. et al., 2003; Kirk \& Kronzucker, 2005; Duan et al., 2006). De acordo com Kronzucker et al. (1999, 2000), o $\mathrm{NO}_{3}{ }^{-}$formado na rizosfera tem importância fundamental na nutrição do arroz, porém pouco se sabe sobre a intensidade da nitrificação e a proporção entre $\mathrm{NH}_{4}{ }^{+} \mathrm{e} \mathrm{NO}_{3}{ }^{-}$resultante desse processo e disponível para a planta.

Como existe a dificuldade de se monitorar a quantidade de $\mathrm{NO}_{3}{ }^{-}$que pode ser formada nessas regiões, persiste a dúvida sobre a proporção entre $\mathrm{NH}_{4}^{+}$ e $\mathrm{NO}_{3}{ }^{-}$que promove o maior aproveitamento do $\mathrm{Ne}$ seu efeito sobre a absorção de outros nutrientes. Assim, este trabalho foi conduzido com o objetivo de avaliar o crescimento do arroz submetido à aplicação de diferentes proporções de $\mathrm{NH}_{4}{ }^{+}$e de $\mathrm{NO}_{3}{ }^{-}$em solução nutritiva.

\section{MATERIAL E MÉTODOS}

O experimento foi conduzido em casa de vegetação do Departamento de Solos da Universidade Federal do Rio Grande do Sul (Porto Alegre - RS) no período de janeiro a fevereiro de 2008. As unidades experimentais (UEs) foram constituídas de recipientes de polietileno com capacidade para $10 \mathrm{~L}$. Como substrato, foi utilizado poliestireno cristal granulado, material inerte e de densidade superior à da água, objetivando criar um meio adequado para o desenvolvimento e a distribuição do sistema radicular do arroz.

O experimento foi conduzido em solução nutritiva, e os tratamentos constaram das seguintes proporções entre $\mathrm{NH}_{4}{ }^{+}$e $\mathrm{NO}_{3}{ }^{-}:$100:0, 75:25, 50:50, 25:75 e 0:100. Para compor os tratamentos, foram utilizadas as seguintes fontes: $\mathrm{NH}_{4} \mathrm{NO}_{3},\left(\mathrm{NH}_{4}\right)_{2} \mathrm{SO}_{4}, \mathrm{Ca}\left(\mathrm{NO}_{3}\right)_{2} \cdot \mathrm{H}_{2} \mathrm{O}$,
$\mathrm{Mg}\left(\mathrm{NO}_{3}\right)_{2}, \mathrm{KNO}_{3}, \mathrm{NH}_{4} \mathrm{H}_{2} \mathrm{PO}_{4}\left(\mathrm{NH}_{4}\right)_{2} \mathrm{HPO}_{4}, \mathrm{NH}_{4} \mathrm{Cl}$, $\mathrm{MgSO}_{4} \cdot 7 \mathrm{H}_{2} \mathrm{O}, \mathrm{CaSO}_{4} \cdot 2 \mathrm{H}_{2} \mathrm{O}, \mathrm{KCl}$ e $\mathrm{KH}_{2} \mathrm{PO}_{4}$. As concentrações finais de cada solução são apresentadas no quadro 1. A solução contendo micronutrientes foi composta por: $\mathrm{Mn}-\left(\mathrm{MnSO}_{4} \cdot \mathrm{H}_{2} \mathrm{O}-0,0047 \mathrm{mmol} \mathrm{L}^{-1}\right)$, $\mathrm{Cu}-\left(\mathrm{CuSO}_{4} .5 \mathrm{H}_{2} \mathrm{O}-0,0047 \mathrm{mmol} \mathrm{L}^{-1}\right), \mathrm{Zn}-$ $\left(\mathrm{ZnSO}_{4} \cdot 7 \mathrm{H}_{2} \mathrm{O}-0,0015 \mathrm{mmol} \mathrm{L}-1\right), \mathrm{B}-\left(\mathrm{H}_{3} \mathrm{BO}_{3}-\right.$ $\left.0,023 \mathrm{mmol} \mathrm{L}^{-1}\right)$, Mo - $\left(\mathrm{NaMoO}_{4} \cdot 2 \mathrm{H}_{2} \mathrm{O}-\right.$ $\left.0,00011 \mathrm{mmol} \mathrm{L}^{-1}\right)$ e Fe - $\left(\mathrm{Fe}-\mathrm{EDTA}-0,5 \mathrm{mg} \mathrm{L}^{-1}\right) . \mathrm{O}$ $\mathrm{pH}$ das soluções foi ajustado até $6,0 \mathrm{com} \mathrm{HCl}$ e $\mathrm{NaOH}$ $0,1 \mathrm{~mol} \mathrm{~L}^{-1}$.

O genótipo de arroz utilizado foi o IRGA 417, cultivar (Indica) de ciclo precoce, pertencente ao grupo moderno. As sementes foram previamente embebidas em água durante $24 \mathrm{~h}$, das quais, cinco sementes foram semeadas diretamente em cada UE, no substrato, contendo somente água destilada. As UEs foram dispostas obedecendo a um delineamento inteiramente casualizado com três repetições, totalizando 15 UEs. Aos 4 dias após a emergência (DAE) foi iniciado o fornecimento da solução nutritiva, sendo que, cada UE recebeu 3,0 L. Aos 5 DAE, momento em que as plantas iniciavam a emissão da terceira folha, foi realizado um desbaste, mantendose duas plantas em cada UE. As UEs foram cobertas com uma lâmina de poliestireno expandido com espessura de $2,5 \mathrm{~cm}$, com um orifício central, para dar suporte às plantas, evitar a entrada direta de luz e reduzir a evaporação da solução. As soluções foram trocadas seis vezes durante a condução do experimento, sob o critério de manter o $\mathrm{pH}$ entre 5,5 e 6,0 ou quando houvesse redução no nível de solução causada pela evapotranspiração.

As plantas foram colhidas aos 42 DAE, momento que coincide com o estádio de desenvolvimento V9 (Counce, 2000). As plantas foram seccionadas aproximadamente $3,0 \mathrm{~cm}$ acima da base, separando a parte aérea. Os $3,0 \mathrm{~cm}$ de colmo restantes foram externamente lavados com água deionizada e secos com papel absorvente, de onde, após alguns minutos, houve a ascensão da seiva do xilema. Dos afilhos, foi coletada a seiva com auxílio de seringas, até obter volume suficiente para análise. A coleta do xilema foi realizada no período das 15 às $16 \mathrm{~h}$. As amostras de xilema foram transferidas para tubos do tipo

Quadro 1. Concentração da solução nutritiva que compôs as proporções de $\mathrm{N}_{-} \mathrm{NH}_{4}^{+} \mathrm{e} \mathrm{N}^{-\mathrm{NO}_{3}}{ }^{-}$

\begin{tabular}{|c|c|c|c|c|c|}
\hline \multirow{2}{*}{ Nutriente } & \multicolumn{5}{|c|}{ Tratamento } \\
\hline & $\mathrm{NH}_{4}^{+}$100: $0 \mathrm{NO}_{3}^{-}$ & $\mathrm{NH}_{4}^{+} 75: 25 \mathrm{NO}_{3}^{-}$ & $\mathrm{NH}_{4}^{+} 50: 50 \mathrm{NO}_{3}^{-}$ & $\mathrm{NH}_{4}^{+} 25: 75 \mathrm{NO}_{3}^{-}$ & $\mathrm{NH}_{4}^{+} 0: 100 \mathrm{NO}_{3}^{-}$ \\
\hline & & & $\mathrm{mmol} \mathrm{L}^{-1}$ & & \\
\hline $\mathrm{N}$ & 5.00 & 5.00 & 5.00 & 5.00 & 5.00 \\
\hline $\mathrm{P}$ & 1.00 & 1.00 & 1.00 & 1.00 & 1.00 \\
\hline $\mathrm{K}$ & 2.00 & 2.00 & 2.00 & 2.00 & 2.00 \\
\hline $\mathrm{Ca}$ & 2.00 & 2.00 & 2.00 & 2.00 & 2.25 \\
\hline $\mathrm{Mg}$ & 1.25 & 1.25 & 1.25 & 1.25 & 1.25 \\
\hline $\mathrm{S}$ & 5.25 & 4.50 & 3.25 & 2.00 & 1.00 \\
\hline $\mathrm{Cl}$ & 2.00 & 1.00 & 1.00 & 1.00 & 1.00 \\
\hline
\end{tabular}


"eppendorf" e imediatamente congeladas. No xilema foram determinados os teores dos íons $\mathrm{NH}_{4}{ }^{+}, \mathrm{K}^{+}, \mathrm{Ca}^{2+}$, $\mathrm{Mg}^{2+} \mathrm{e} \mathrm{NO}_{3}^{-}$pelo método analítico de separação por cromatografia iônica, em cromatógrafo DIONEX, modelo DX-120, no modo aberto. As condições dessa análise foram: cátions: $\mathrm{NH}_{4}{ }^{+}, \mathrm{K}^{+}, \mathrm{Ca}^{2+} \mathrm{e} \mathrm{Mg}^{2+}$ foram quantificados com coluna S16 $(5 \times 250 \mathrm{~mm})$ e précoluna G $16(5 \times 50 \mathrm{~mm})$, tendo como eluente solução aquosa de ácido sulfúrico na concentração de $25 \mathrm{mmol} \mathrm{L}^{-1}$, com fluxo de 1,09 $\mathrm{mL} \mathrm{min}^{-1}$. O ânion $\mathrm{NO}_{3}{ }^{-}$foi quantificado com uma coluna $\mathrm{S} 22$ $(4 \times 250 \mathrm{~mm})$ e pré-coluna G22 $(4 \times 50 \mathrm{~mm})$, tendo como eluente solução aquosa de $\mathrm{Na}_{2} \mathrm{CO}_{3} / \mathrm{NaHCO}_{3}$, na concentração de $3,5: 1 \mathrm{mmol} \mathrm{L}^{-1}$, com fluxo de $1,06 \mathrm{~mL} \mathrm{~min}^{-1}$.

Após a coleta da seiva, cortou-se o restante dos colmos na base da planta, para avaliação da matéria seca da parte aérea. A solução nutritiva dos vasos foi drenada, e as raízes, retiradas e lavadas com água destilada. A parte aérea e as raízes foram secas em estufa a $60^{\circ} \mathrm{C}$ até peso constante, para determinação da biomassa. As amostras foram moídas em micromoinho e submetidas à digestão ácida, para posterior determinação dos teores de N, K, Ca, Mg (Tedesco et al., 1995). Os resultados foram submetidos à análise da variância $(\mathrm{p}<0,05)$, com a comparação entre médias dos tratamentos pelo teste do DMS $(\mathrm{p}<0,05)$.

\section{RESULTADOS E DISCUSSÃO}

\section{Suprimento de $\mathrm{NH}_{4}{ }^{+}$e $\mathrm{NO}_{3}^{-}$e produção de biomassa}

A produção de biomassa da parte aérea, raiz e total diferiu entre as proporções de $\mathrm{NH}_{4}{ }^{+} \mathrm{e} \mathrm{NO}_{3}{ }^{-}$testadas (Quadro 2). O maior rendimento de biomassa de parte aérea e total foi obtido nas proporções em que o $\mathrm{N}$ foi fornecido de forma combinada (Quadro 2), indicando que a planta de arroz apresenta melhor desenvolvimento quando o $\mathrm{NH}_{4}{ }^{+}$é fornecido juntamente com o $\mathrm{NO}_{3}{ }^{-}$. Embora não tenha havido diferenças $(\mathrm{p}>0,05)$ entre as três proporções em que o $\mathrm{N}$ foi fornecido de forma combinada (Quadro 2), as plantas dos tratamentos $\mathrm{NH}_{4}^{+}$75:25 $\mathrm{NO}_{3}^{-}$e $\mathrm{NH}_{4}^{+}$25:75 $\mathrm{NO}_{3}^{-}$ apresentaram efeitos negativos, característicos do excesso de $\mathrm{NH}_{4}{ }^{+}$e $\mathrm{NO}_{3}{ }^{-}$. A menor produção de biomassa da parte aérea nesses tratamentos ocorreu porque os sintomas de toxidez aparecem primeiro nas folhas velhas, após estarem totalmente desenvolvidas, evoluindo gradativamente para as demais. A menor produção de biomassa nas proporções $\mathrm{NH}_{4}{ }^{+}$100:0 $\mathrm{NO}_{3}{ }^{-}$ e $\mathrm{NH}_{4}{ }^{+}$0:100 $\mathrm{NO}_{3}{ }^{-}$(Quadro 2) indica a resposta da planta ao efeito da toxidez causada pelo $\mathrm{NH}_{4}{ }^{+}$e pelo $\mathrm{NO}_{3}{ }^{-}$, quando estes íons foram supridos isoladamente. Já na proporção $\mathrm{NH}_{4}{ }^{+} 50: 50 \mathrm{NO}_{3}^{-}$, as plantas desenvolveram-se normalmente, sem qualquer sintoma visível de toxidez, indicando que o balanço entre as duas fontes de $\mathrm{N}$ pode ser a proporção mais favorável ao desenvolvimento do arroz. Redução no crescimento de parte aérea e raízes de arroz também foi observada por Li et al. (2006) e Cao et al. (2008) quando o $\mathrm{NH}_{4}{ }^{+}$foi a única fonte de $\mathrm{N}$.

No tratamento $\mathrm{NH}_{4}{ }^{+}$100:0 $\mathrm{NO}_{3}{ }^{-}$as plantas apresentaram sintomas visíveis de toxidez por $\mathrm{NH}_{4}{ }^{+}$aos 27 DAE. Na proporção $\mathrm{NH}_{4}{ }^{+} 75: 25 \mathrm{NO}_{3}{ }^{-}$, os sintomas se manifestaram com menor intensidade e somente aos 35 DAE. A toxidez ocorreu nas folhas mais velhas, na forma de manchas cloróticas, evoluindo para a necrose da folha, da bainha para o centro, sugerindo que a toxidez por $\mathrm{NH}_{4}{ }^{+}$tenha relação direta com o efeito acumulativo desses íons na célula (Wang et al., 1994; Britto et al., 2001). Isso ocorre devido à entrada contínua de $\mathrm{NH}_{4}{ }^{+}$por transportadores de baixa afinidade ou canais na membrana, interferindo no controle da entrada do $\mathrm{NH}_{4}{ }^{+}$na célula, causando seu acúmulo (Wang et al., 1994; Kronzucker et al., 1999) e, consequentemente, uma série de distúrbios fisiológicos e a morte das células (Britto \& Kronzucker, 2002 , 2005). O comportamento acumulativo desse cátion e sua relação com a toxidez também foram relatados por Britto et al. (2001), que encontraram concentrações de $\mathrm{NH}_{4}{ }^{+}$superiores a $100 \mathrm{mmol} \mathrm{L}^{-1}$ no citosol de células de cevada e de arroz, quando submetidas à concentrações externas de $10,0 \mathrm{mmol} \mathrm{L}^{-1}$ de $\mathrm{NH}_{4}{ }^{+}$. Sintomas de toxidez semelhantes também

Quadro 2. Produção de biomassa da parte aérea, raízes, total e relação raiz:parte aérea de arroz em função de proporções de $\mathrm{N}-\mathrm{NH}_{4}{ }^{+}$e $\mathrm{N}-\mathrm{NO}_{3}{ }^{-}$em solução nutritiva

\begin{tabular}{|c|c|c|c|c|}
\hline Tratamento & Parte aérea & Raiz & Total & Raiz/Parte aérea \\
\hline & \multicolumn{4}{|c|}{ - g/vaso } \\
\hline $\mathrm{NH}_{4}^{+} 100: 0 \mathrm{NO}_{3}^{-}$ & $9,81 b^{(1)}$ & $0,95 \mathrm{c}$ & $10,8 \mathrm{~b}$ & $0,10 \mathrm{~d}$ \\
\hline $\mathrm{NH}_{4}^{+} 75: 25 \mathrm{NO}_{3}^{-}$ & $15,2 \mathrm{a}$ & $2,06 \mathrm{~b}$ & $17,2 \mathrm{a}$ & $0,14 \mathrm{~cd}$ \\
\hline $\mathrm{NH}_{4}^{+}+50: 50 \mathrm{NO}_{3}^{-}$ & $15,1 \mathrm{a}$ & $2,43 \mathrm{~b}$ & $17,5 \mathrm{a}$ & $0,16 \mathrm{c}$ \\
\hline $\mathrm{NH}_{4}^{+} 25: 75 \mathrm{NO}_{3}^{-}$ & $17,1 \mathrm{a}$ & $3,50 \mathrm{a}$ & $20,6 \mathrm{a}$ & $0,20 \mathrm{~b}$ \\
\hline $\mathrm{NH}_{4}^{+} 0: 100 \mathrm{NO}_{3}^{-}$ & $6,7 \mathrm{~b}$ & $1,72 \mathrm{bc}$ & $8,7 \mathrm{~b}$ & $0,27 \mathrm{a}$ \\
\hline CV (\%) & 18,6 & 20,8 & 18,2 & 12,7 \\
\hline
\end{tabular}

${ }^{(1)}$ Médias seguidas por letras iguais nas colunas não diferem entre si pelo teste do DMS $(p>0,05)$. 
foram observados por Britto \& Kronzucker (2002) e Kronzucker et al. (2000) em diversas culturas.

É importante considerar a concentração dos íons $\mathrm{NH}_{4}{ }^{+}$e $\mathrm{NO}_{3}^{-}$em cada proporção testada na disponibilidade desses íons para a planta. Mesmo que possam ser encontradas concentrações superiores a 10,0 $\mathrm{mmol} \mathrm{L}^{-1}$ de $\mathrm{NH}_{4}^{+}$em solos cultivados (Wolt, 1994), pode-se dizer que as concentrações de 5,0 e $3,75 \mathrm{mmol} \mathrm{L}^{-1}$ de $\mathrm{NH}_{4}^{+}$nas proporções $\mathrm{NH}_{4}{ }^{+} 100: 0$ $\mathrm{NO}_{3}^{-}$e $\mathrm{NH}_{4}{ }^{+} 75: 25 \mathrm{NO}_{3}^{-}$, respectivamente, foram elevadas o suficiente para causar toxidez nas plantas (Quadro 1). Cabe salientar que, como a solução era substituída constantemente, a concentração de $\mathrm{NH}_{4}{ }^{+}$ foi mantida praticamente constante durante todo o período de cultivo, causando a toxidez, ao contrário do que acontece na lavoura, onde a disponibilidade de $\mathrm{N}$ sofre flutuações acentuadas durante o ciclo da cultura nos períodos entre aplicações de fertilizantes. O rápido decréscimo da concentração de $\mathrm{NH}_{4}{ }^{+}$no solo pode ser uma das razões pelas quais não são observados sintomas de toxidez ao longo do ciclo da cultura quando cultivado em lavoura.

Diferentes hipóteses foram elaboradas na tentativa de explicar as causas da toxidez por $\mathrm{NH}_{4}{ }^{+}$, entre as quais estão a relação da entrada excessiva de $\mathrm{NH}_{4}{ }^{+}$ com a despolarização da membrana plasmática e do tonoplasto, a acidificação das organelas celulares, na tentativa de manter o potencial elétrico das membranas, mudanças no status de carboidratos das plantas, o desacoplamento da fotofosforilação e, consequentemente, distúrbios fisiológicos que levam à morte das células e do tecido (Britto \& Kronzucker, 2002, 2005). Outro mecanismo que estaria associado à toxidez por $\mathrm{NH}_{4}{ }^{+}$foi proposto por Kronzucker et al. (2000) e Britto et al. (2001). Para esses autores, o fato de a absorção excessiva de $\mathrm{NH}_{4}{ }^{+}$ocorrer por transportadores de baixa afinidade e ocupar canais de outros cátions indica que esse possa ser o motivo de se criar um mecanismo de efluxo do $\mathrm{NH}_{4}{ }^{+}$para fora da célula. Esse mecanismo foi denominado de ciclagem fútil por esses autores, e o efeito resultante é um elevado gasto energético necessário para bombear o excesso de $\mathrm{NH}_{4}{ }^{+}$para fora da célula. Conforme esses autores, aproximadamente $80 \%$ do $\mathrm{NH}_{4}{ }^{+}$absorvido pode sofrer efluxo por esse processo, e o elevado consumo de ATP, resulta no aumento da respiração nas raízes, determinando redução no seu crescimento. De maneira semelhante, o efeito negativo da fonte nítrica fornecida isoladamente sobre o desenvolvimento da planta mantém relação com o consumo de ATP. O menor crescimento da parte aérea na proporção $\mathrm{NH}_{4}{ }^{+}$ 0:100 $\mathrm{NO}_{3}{ }^{-}$(Quadro 2) está associado ao gasto de ATP necessário para a assimilação, síntese e translocação de fotoassimilados da parte aérea para as raízes (Reddy \& Menary, 1990). Além de fonte de $\mathrm{N}$, o íon $\mathrm{NO}_{3}{ }^{-}$, quando detectado pelas células da raiz, atua como sinalizador bioquímico sobre a expressão de genes relacionados com o seu transporte na membrana celular, comumente denominados de NRTs (Nitrate transporters). A maior expressão desses genes determina aumento na quantidade de $\mathrm{NO}_{3}{ }^{-}$absorvida pela planta em função da disponibilidade desse íon no meio externo. Uma outra resposta de sinalização bioquímica é responsável por ativar a alocação de fotoassimilados da parte aérea para as raízes, em resposta à necessidade de estimular o desenvolvimento do sistema radicular e auxiliar na assimilação desse íon (Forde, 2002). Assim, a maior disponibilidade de $\mathrm{NO}_{3}^{-}$na proporção $\mathrm{NH}_{4}{ }^{+}$0:100 $\mathrm{NO}_{3}^{-}$pode ter sido a causa da inibição do desenvolvimento da parte aérea da planta (Quadro 2). Por outro lado, à medida que aumentou a proporção de $\mathrm{NO}_{3}{ }^{-}$, houve aumento na produção de biomassa de raiz até o tratamento $\mathrm{NH}_{4}{ }^{+}$ 25:75 $\mathrm{NO}_{3}{ }^{-}$(Quadro 2). Nesse caso, a variação do crescimento das raízes entre os tratamentos pode ser atribuída ao efeito do íon $\mathrm{NO}_{3}{ }^{-}$sobre o estímulo ao desenvolvimento de raízes e também sobre a redução da toxidez por $\mathrm{NH}_{4}{ }^{+}$. Entretanto, houve também acentuada redução no desenvolvimento de raízes na proporção $\mathrm{NH}_{4}^{+}$0:100 $\mathrm{NO}_{3}{ }^{-}$(Quadro 2).

Um dos mecanismos pelos quais as plantas ajustam o desbalanço dos recursos externos/exógenos é pela alocação de energia e fotoassimilados para os órgãos que estão envolvidos na obtenção de recursos nutricionais (Marschner, 1995; Epstein \& Bloom, 2006). A variação do desenvolvimento da parte aérea e das raízes em função do fornecimento de $\mathrm{NH}_{4}{ }^{+} \mathrm{e}$ $\mathrm{NO}_{3}{ }^{-}$permite criar uma relação denominada de raiz/ parte aérea. Essa relação é útil para avaliar o efeito desses íons nos processos metabólicos relacionados à assimilação, translocação de fotoassimilados e, ou, respostas a distúrbios fisiológicos na planta (Haynes $\&$ Goh, 1978). À medida que aumentou a concentração de $\mathrm{NO}_{3}{ }^{-}$nos tratamentos, houve aumento correspondente na relação raiz/parte aérea até a proporção $\mathrm{NH}_{4}{ }^{+}$25:75 $\mathrm{NO}_{3}{ }^{-}$(Quadro 2). Entretanto, na proporção $\mathrm{NH}_{4}^{+}$0:100 $\mathrm{NO}_{3}^{-}$houve também redução na produção de biomassa de parte aérea e raízes em relação às proporções em que o $\mathrm{N}$ foi fornecido de forma combinada, influenciando a relação raiz/parte aérea (Quadro 2).

De acordo com Forde (2002), o $\mathrm{NO}_{3}{ }^{-}$atua no estímulo ao desenvolvimento de raízes e determina que esqueletos carbônicos oriundos da fotossíntese sejam translocados da parte aérea para as raízes, causando desequilíbrio no balanço energético da planta. Aliado a isso, o aumento da absorção de $\mathrm{NO}_{3}{ }^{-}$, embora desejável, está associada ao maior gasto de energia necessário para a assimilação desse íon, que é de 12 ATPs, comparado aos 2 ATPs necessários para assimilar o $\mathrm{NH}_{4}^{+}$(Kronzucker et al., 2001; Britto \& Kronzucker, 2002).

Outro efeito associado à redução do crescimento da parte aérea deve-se à entrada excessiva de $\mathrm{NH}_{4}{ }^{+}$ nas células da raiz. Nos tratamentos $\mathrm{NH}_{4}{ }^{+}$100:0 $\mathrm{NO}_{3}{ }^{-}$ e $\mathrm{NH}_{4}{ }^{+} 75: 25 \mathrm{NO}_{3}{ }^{-}$, onde foi observada toxidez pelo íon $\mathrm{NH}_{4}{ }^{+}$, houve também menor produção de biomassa de parte aérea, influenciando a relação raiz/parte aérea 
( $p<0,05)$ (Quadro 2). Considerando que a assimilação do $\mathrm{NH}_{4}{ }^{+}$ocorre principalmente nas raízes, a elevação da sua concentração nas células aumenta a demanda por esqueletos de $\mathrm{C}$ oriundos do ciclo dos ácidos tricarboxílicos (Oaks, 1992). Dessa forma, além dos problemas de toxidez, já discutidos, a assimilação de grandes quantidades de $\mathrm{NH}_{4}{ }^{+}$em amidas e aminoácidos na raiz e sua translocação para a parte aérea também determinam um elevado gasto de energia para a planta, fazendo com que haja inibição do desenvolvimento da parte aérea. De acordo com Schjoerring et al. (2002), o transporte eficiente de carboidratos para as raízes pode favorecer a metabolização do $\mathrm{NH}_{4}^{+}$, evitando o transporte para a parte aérea, e, assim, atuar como mecanismo de prevenção à toxidez. O efeito dos tratamentos sobre o desenvolvimento das raízes é ilustrado na figura 1 .

\section{Conteúdo de cátions e ânions na seiva do} xilema

A concentração de $\mathrm{NO}_{3}{ }^{-}$no xilema aumentou à medida que a proporção de $\mathrm{NO}_{3}{ }^{-}$na solução foi maior nos tratamentos (Quadro 3). Ainda que as rotas de assimilação do $\mathrm{NO}_{3}^{-}$sejam altamente reguladas por diferentes mecanismos bioquímicos, o passo mais importante da regulação parece ser o processo de influxo na membrana plasmática das células corticais e epidérmicas da raiz (Forde, 2002). O influxo de $\mathrm{NO}_{3}{ }^{-}$ é um processo ativo, governado por um gradiente de $\mathrm{H}^{+}$e catalisado por uma combinação de um sistema de transportadores de alta (HATS) e baixa afinidade (LATS) (Forde, 2002), do tipo simporte, com a entrada simultânea de $\mathrm{NO}_{3}^{-}$e $\mathrm{H}^{+}$e consumo de ATP (Taiz \& Zieger, 2008). A regulação do influxo é, portanto, dependente da expressão gênica que codifica os transportadores na membrana plasmática, tendo como sinalizador local e de longa distância o próprio íon $\mathrm{NO}_{3}{ }_{3}$. Dessa forma, a absorção do $\mathrm{NO}_{3}{ }^{-}$, a indução de rotas metabólicas ligadas à sua assimilação e a reprogramação do metabolismo do C (Crawford, 1995; Coruzzi \& Bush, 2001) ocorreram basicamente em resposta às flutuações na disponibilidade desse íon no meio externo (Forde, 2002). Isso está de acordo com os resultados deste experimento, no qual o aumento gradativo da concentração desse íon na seiva xilema sugere que até a concentração de $5,0 \mathrm{mmol} \mathrm{L}^{-1} \mathrm{de} \mathrm{NO}_{3}{ }^{-}$ ocorreu a formação contínua de transportadores para esse íon (Williams \& Miller, 2001). De acordo com Forde (2002), outro ponto importante no controle da absorção de $\mathrm{N}$ está relacionado ao estado nutricional da planta, o que caracteriza um efeito de feedback. No entanto, neste estudo, a absorção contínua de $\mathrm{NO}_{3}{ }^{-}$ em virtude da disponibilidade constante na solução proporcionou a entrada de elevadas quantidades desse ânion, resultando na translocação de quantidades prejudiciais ao desenvolvimento das plantas, a partir da proporção $\mathrm{NH}_{4}{ }^{+}$25:75 $\mathrm{NO}_{3}^{-}$. O gasto energético necessário para realizar a absorção, a síntese e o transporte de assimilados da parte aérea para as raízes, como também o consumo de ATP necessário para assimilar o $\mathrm{NO}_{3}{ }^{-}$, são as principais razões pela qual o desenvolvimento da planta é alterado quando submetida a elevadas concentrações de $\mathrm{NO}_{3}{ }^{-}$no meio (Forde, 2002; Britto \& Kronzucker, 2005).

$\mathrm{O}$ conteúdo de $\mathrm{NH}_{4}{ }^{+}$na seiva do xilema não diferiu ( $\mathrm{p}>0,05)$ entre as proporções de $\mathrm{NH}_{4}{ }^{+}$e $\mathrm{NO}_{3}{ }^{-}$ (Quadro 3). Embora sem diferença estatística, o efeito dos tratamentos sobre o desenvolvimento das plantas pode ser justificado pela toxidez por $\mathrm{NH}_{4}{ }^{+}$observada nas proporções $\mathrm{NH}_{4}{ }^{+}$100:0 $\mathrm{NO}_{3}{ }^{-} \mathrm{e} \mathrm{NH}_{4}{ }^{+}$75:25 $\mathrm{NO}_{3}{ }^{-}$. A diferença da concentração de $\mathrm{NH}_{4}{ }^{+}$no xilema nas proporções $\mathrm{NH}_{4}{ }^{+}$100:0 $\mathrm{NO}_{3}^{-}{ }^{-} \mathrm{e} \mathrm{NH}_{4}{ }^{+} 75: 25 \mathrm{NO}_{3}^{-}$, em relação à proporção $\mathrm{NH}_{4}{ }^{+} 50: 50 \mathrm{NO}_{3}{ }^{-}$, onde não foi observada toxidez, foi de 6,29 e $4,34 \mathrm{mmol} \mathrm{L}^{-1}$ respectivamente (Quadro 3), indicando que, nas condições deste experimento, a partir de $28,76 \mathrm{mmol} \mathrm{L}^{-1}$

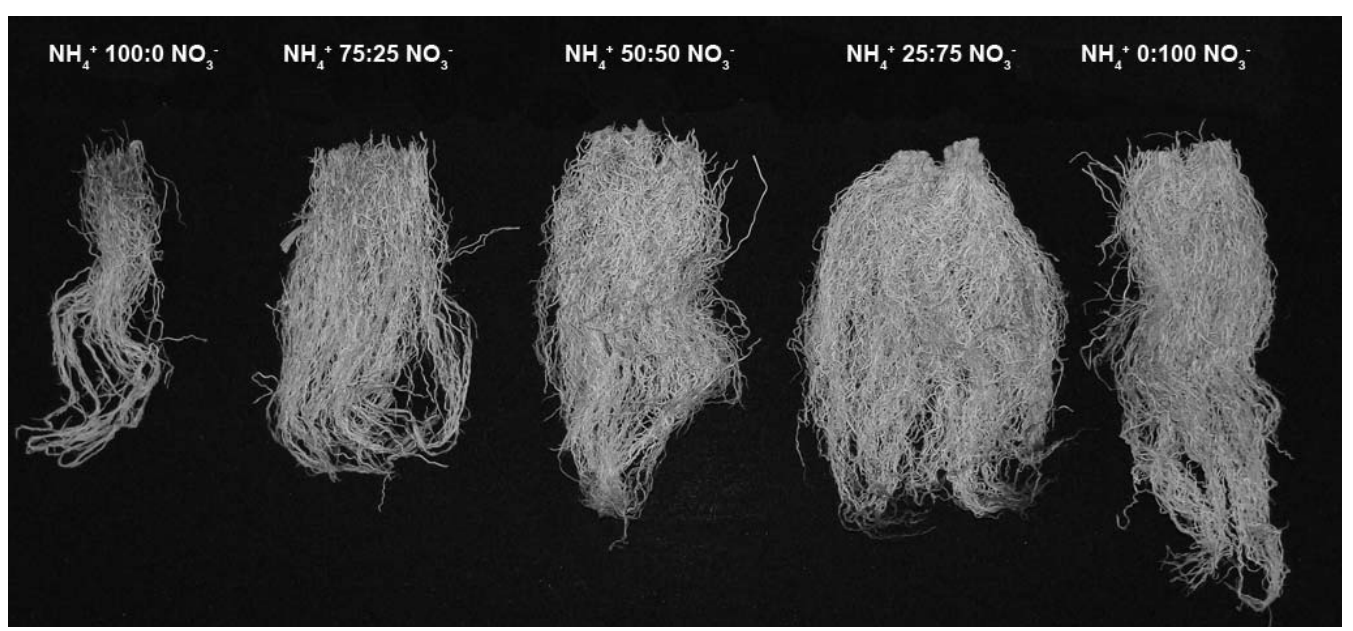

Figura 1. Desenvolvimento do sistema radicular do arroz IRGA 417 em função de proporções de $\mathrm{N}_{-} \mathrm{NH}_{4}{ }^{+} \mathrm{e} \mathrm{N}_{-}$ $\mathrm{NO}_{3}{ }^{-}$em solução nutritiva. 
de $\mathrm{NH}_{4}{ }^{+}$, existe a possibilidade de a concentração ser elevada o suficiente para que ocorra o transporte excessivo até a parte aérea e seja caracterizada a toxidez. Embora as análises de monitoramento da solução nutritiva não tenham detectado $\mathrm{NH}_{4}{ }^{+}$na proporção $\mathrm{NH}_{4}^{+}$0:100 $\mathrm{NO}_{3}^{-}$(dados não apresentados), a concentração do $\mathrm{NH}_{4}{ }^{+}$na seiva do xilema neste tratamento apresentou valores próximos aos das proporções que continham $\mathrm{NH}_{4}^{+}$(Quadro 3). A presença desse $\mathrm{NH}_{4}{ }^{+}$pode estar relacionada com a redução do $\mathrm{NO}_{3}^{-}$nas células das raízes, com consequente translocação do $\mathrm{NH}_{4}{ }^{+}$até a parte aérea. De acordo com Yoneyama \& Kumazawa (1975), embora a maior parte do $\mathrm{NO}_{3}{ }^{-}$seja assimilada no citosol das células do mesofilo foliar, também é comum a presença da enzima $\mathrm{NO}_{3}{ }^{-}$redutase em células das raízes.

À medida que a proporção de $\mathrm{NH}_{4}{ }^{+}$foi aumentada nos tratamentos, houve redução na absorção de $\mathrm{K}, \mathrm{Ca}$ e $\mathrm{Mg}$ (Quadro 3), indicando que o $\mathrm{NH}_{4}{ }^{+}$altera a absorção desses cátions, por ocupar os canais transportadores de baixa afinidade ou menor seletividade na membrana. A redução da absorção de $\mathrm{K}, \mathrm{Ca}$ e $\mathrm{Mg}$ pelo $\mathrm{NH}_{4}{ }^{+}$foi de 28,28 e $37 \%$ quando comparadas as proporções $\mathrm{NH}_{4}{ }^{+}$0:100 $\mathrm{NO}_{3}{ }^{-}$e $\mathrm{NH}_{4}{ }^{+}$ 100:0 $\mathrm{NO}_{3}{ }^{-}$(Quadro 3). Conforme já discutido, a influência negativa do $\mathrm{NH}_{4}{ }^{+}$sobre a absorção desses cátions pode levar a deficiências na planta, principalmente considerando a importância de $\mathrm{K}, \mathrm{Ca}$ e Mg na regulação de diversos processos metabólicos e na composição de moléculas e tecidos.

Considerando o fornecimento de igual concentração de $\mathrm{NH}_{4}{ }^{+}$e de $\mathrm{NO}_{3}{ }^{-}$na proporção $\mathrm{NH}_{4}{ }^{+} 50: 50 \mathrm{NO}_{3}{ }^{-}$, observa-se que a concentração de $\mathrm{NO}_{3}{ }^{-}$translocado no xilema é 3,33 vezes maior do que a concentração do $\mathrm{NH}_{4}{ }^{+}$(Quadro 3). A explicação para o menor teor de $\mathrm{NH}_{4}{ }^{+}$no xilema pode ser a assimilação desse íon, que ocorre predominantemente nas raízes, com posterior translocação para a parte aérea na forma de aminoácidos (Epstein \& Bloom, 2006). Embora não tenham sido realizadas determinações do teor de $\mathrm{NO}_{3}{ }^{-}$ na parte aérea das plantas, pode-se usar o teor de $\mathrm{NO}_{3}{ }^{-}$ translocado na seiva do xilema no tratamento $\mathrm{NH}_{4}{ }^{+}$ $0: 100 \mathrm{NO}_{3}^{-}$, como evidência da alta concentração desse íon nas células (Quadro 3), e esta pode ser a causa da inibição da produção de biomassa de raízes e parte aérea (Quadro 2) decorrente do gasto energético.

\section{Nutrientes na biomassa vegetal}

Os teores de $\mathrm{N}$ e $\mathrm{K}$ total na biomassa da parte aérea não diferiram entre as proporções de $\mathrm{NH}_{4}{ }^{+} \mathrm{e}$ $\mathrm{NO}_{3}{ }^{-}$(Quadro 4). Por outro lado, nas raízes houve diferença no teor de $\mathrm{N}$ e K ; o tratamento $\mathrm{NH}_{4}{ }^{+} 50: 50$ $\mathrm{NO}_{3}{ }^{-}$apresentou teores superiores aos demais (Quadro 4).

Embora a análise do xilema tenha indicado a interferência do $\mathrm{NH}_{4}{ }^{+}$na absorção do $\mathrm{K}$, a ausência de variação do teor total de $\mathrm{K}$ no tecido da parte aérea pode estar relacionada à manutenção de concentrações mais elevadas na célula em virtude da regulação osmótica, que controla a abertura e o fechamento de estômatos (Epstein \& Bloom, 2006; Taiz \& Zieger, 2008). A concentração dentro de células "guardas" da folha normalmente estão em torno de $100 \mathrm{mmol} \mathrm{L}^{-1} \mathrm{e}$ podem alcançar valores de 400 a $800 \mathrm{mmol} \mathrm{L}^{-1}$ por ocasião da abertura estomática (Taiz \& Zieger, 2008); portanto, muito superiores aos observados na seiva do xilema (Quadro 4). Por sua vez, a variação do teor de $\mathrm{K}$ observada no tecido das raízes pode estar relacionada às condições nos sítios de absorção no momento da coleta do material, em resposta aos tratamentos. A concentração de íons no tecido das raízes reflete uma condição mais próxima do que está sendo absorvido no momento da coleta, ao contrário de se considerar o teor nas células da parte aérea, que apresentam regulação diferenciada de acordo com os processos metabólicos envolvidos na assimilação e regulação da concentração de nutrientes, assim como no armazenamento de nutrientes nos vacúolos (Epstein \& Bloom, 2006; Taiz \& Zieger, 2008).

Os teores de Ca e de Mg na biomassa da parte aérea e raiz aumentaram à medida que a proporção de $\mathrm{NH}_{4}{ }^{+}$na solução decresceu (Quadro 4), indicando que a absorção total desses cátions foi alterada pela presença do $\mathrm{NH}_{4}{ }^{+} \mathrm{e}$ é dependente da sua concentração. Esse comportamento tem sido atribuído ao tipo de transportador envolvido na absorção desses cátions,

Quadro 3. Teores de nutrientes na seiva do xilema de plantas de arroz em função de proporções de $\mathrm{N}^{-\mathrm{NH}_{4}}{ }^{+}$ e $\mathrm{N}-\mathrm{NO}_{3}{ }^{-}$em solução nutritiva

\begin{tabular}{|c|c|c|c|c|c|}
\hline Tratamento & $\mathrm{NO}_{3}^{-}$ & $\mathrm{NH}_{4}^{+}$ & $\mathbf{K}^{+}$ & $\mathrm{Ca}^{2+}$ & $\mathrm{Mg}^{2+}$ \\
\hline & & & \multicolumn{3}{|c|}{$\mathrm{mmol} \mathrm{L}^{-1}$} \\
\hline $\mathrm{NH}_{4}^{+} 100: 0 \mathrm{NO}_{3}^{-}$ & $0,38 c^{(1)}$ & $33,1 \mathrm{a}$ & $21,3 \mathrm{~b}$ & $0,44 \mathrm{~d}$ & $2,79 \mathrm{~b}$ \\
\hline $\mathrm{NH}_{4}^{+} 75: 25 \mathrm{NO}_{3}^{-}$ & $3,85 \mathrm{c}$ & $35,1 \mathrm{a}$ & $21,6 \mathrm{~b}$ & $0,68 \mathrm{c}$ & $2,71 \mathrm{~b}$ \\
\hline $\mathrm{NH}_{4}^{+} 50: 50 \mathrm{NO}_{3}^{-}$ & $95,81 \mathrm{~b}$ & $28,8 \mathrm{a}$ & $22,1 \mathrm{~b}$ & $0,68 \mathrm{c}$ & $2,72 \mathrm{~b}$ \\
\hline $\mathrm{NH}_{4}^{+} 25: 75 \mathrm{NO}_{3}^{-}$ & $115,89 \mathrm{~b}$ & $25,9 \mathrm{a}$ & $27,8 \mathrm{a}$ & $1,23 \mathrm{~b}$ & $4,27 \mathrm{a}$ \\
\hline $\mathrm{NH}_{4}^{+} 0: 100 \mathrm{NO}_{3}^{-}$ & $231,99 \mathrm{a}$ & $20,7 \mathrm{a}$ & 29,6 a & $1,69 \mathrm{a}$ & $4,44 \mathrm{a}$ \\
\hline $\mathrm{CV}(\%)$ & 18,8 & 34,5 & 10,5 & 11,2 & 11,9 \\
\hline
\end{tabular}

${ }^{(1)}$ Médias seguidas por letras iguais nas colunas não diferem entre si pelo teste do DMS $(p>0,05)$. 
Quadro 4. Teores de nutrientes na biomassa de arroz em função de proporções de $\mathrm{N}_{-} \mathrm{NH}_{4}{ }^{+}$e $\mathrm{N}_{-} \mathrm{NO}_{3}{ }^{-}$ em solução nutritiva

\begin{tabular}{|c|c|c|c|}
\hline Tratamento & Parte aérea & Raiz & Total absorvido \\
\hline & \multicolumn{2}{|c|}{$\mathrm{g} \mathrm{kg}^{-1}$} & \multirow[t]{2}{*}{$\mathrm{mg} / \mathrm{vaso}$} \\
\hline & & $\mathbf{N}$ & \\
\hline $\mathrm{NH}_{4}^{+} 100: 0 \mathrm{NO}_{3}^{-}$ & $38,8 \mathrm{a}^{(1)}$ & $27,2 \mathrm{c}$ & $406 \mathrm{~b}$ \\
\hline $\mathrm{NH}_{4}^{+} 75: 25 \mathrm{NO}_{3}^{-}$ & $41,3 \mathrm{a}$ & $31,2 \mathrm{ab}$ & $692 \mathrm{a}$ \\
\hline $\mathrm{NH}_{4}^{+} 50: 50 \mathrm{NO}_{3}^{-}$ & $41,4 \mathrm{a}$ & $31,4 \mathrm{a}$ & $697 \mathrm{a}$ \\
\hline $\mathrm{NH}_{4}^{+} 25: 75 \mathrm{NO}_{3}^{-}$ & $41,1 \mathrm{a}$ & $19,6 \mathrm{~d}$ & $770 \mathrm{a}$ \\
\hline $\mathrm{NH}_{4}^{+} 0: 100 \mathrm{NO}_{3}^{-}$ & $37,5 \mathrm{a}$ & $28,5 \mathrm{bc}$ & $302 \mathrm{~b}$ \\
\hline \multirow[t]{2}{*}{ CV $(\%)$} & 5,73 & 5,40 & 15,1 \\
\hline & \multicolumn{3}{|c|}{$\mathbf{K}$} \\
\hline $\mathrm{NH}_{4}^{+} 100: 0 \mathrm{NO}_{3}^{-}$ & $44,4 \mathrm{a}$ & $23,1 \mathrm{c}$ & $459 \mathrm{~b}$ \\
\hline $\mathrm{NH}_{4}^{+} 75: 25 \mathrm{NO}_{3}^{-}$ & $45,3 \mathrm{a}$ & $31,3 \mathrm{ab}$ & $753 \mathrm{a}$ \\
\hline $\mathrm{NH}_{4}^{+} 50: 50 \mathrm{NO}_{3}^{-}$ & $44,8 \mathrm{a}$ & $37,1 \mathrm{a}$ & $763 \mathrm{a}$ \\
\hline $\mathrm{NH}_{4}^{+} 25: 75 \mathrm{NO}_{3}^{-}$ & $45,7 \mathrm{a}$ & $18,6 \mathrm{c}$ & $841 \mathrm{a}$ \\
\hline $\mathrm{NH}_{4}^{+}$0:100 NO${ }_{3}^{-}$ & $45,8 \mathrm{a}$ & $30,1 \mathrm{~b}$ & $369 \mathrm{~b}$ \\
\hline \multirow[t]{2}{*}{ CV (\%) } & 6,99 & 12,8 & 18,6 \\
\hline & \multicolumn{3}{|c|}{$\mathbf{C a}$} \\
\hline $\mathrm{NH}_{4}^{+} 100: 0 \mathrm{NO}_{3}^{-}$ & $2,05 \mathrm{~d}$ & $0,45 \mathrm{c}$ & $20,3 \mathrm{c}$ \\
\hline $\mathrm{NH}_{4}^{+} 75: 25 \mathrm{NO}_{3}^{-}$ & $3,08 \mathrm{c}$ & $0,98 \mathrm{~b}$ & $48,7 \mathrm{~b}$ \\
\hline $\mathrm{NH}_{4}^{+} 50: 50 \mathrm{NO}_{3}^{-}$ & $3,48 \mathrm{c}$ & $1,03 \mathrm{~b}$ & $54,1 \mathrm{~b}$ \\
\hline $\mathrm{NH}_{4}^{+} 25: 75 \mathrm{NO}_{3}^{-}$ & $4,33 \mathrm{~b}$ & $1,20 \mathrm{~b}$ & $78,5 \mathrm{a}$ \\
\hline $\mathrm{NH}_{4}^{+} 0: 100 \mathrm{NO}_{3}^{-}$ & $5,78 \mathrm{a}$ & $2,75 \mathrm{a}$ & $43,1 \mathrm{~b}$ \\
\hline \multirow[t]{2}{*}{ CV $(\%)$} & 10,2 & 20,9 & 22,5 \\
\hline & \multicolumn{3}{|c|}{ Mg } \\
\hline $\mathrm{NH}_{4}^{+} 100: 0 \mathrm{NO}_{3}^{-}$ & $4,18 \mathrm{~d}$ & $0,95 \mathrm{c}$ & $41,8 \mathrm{c}$ \\
\hline $\mathrm{NH}_{4}^{+} 75: 25 \mathrm{NO}_{3}^{-}$ & $5,08 \mathrm{c}$ & $1,81 \mathrm{ab}$ & $80,7 \mathrm{~b}$ \\
\hline $\mathrm{NH}_{4}^{+} 50: 50 \mathrm{NO}_{3}^{-}$ & $5,27 \mathrm{bc}$ & $1,75 \mathrm{~b}$ & $82,4 \mathrm{~b}$ \\
\hline $\mathrm{NH}_{4}^{+} 25: 75 \mathrm{NO}_{3}^{-}$ & $5,85 \mathrm{ab}$ & $1,74 \mathrm{~b}$ & $105,8 \mathrm{a}$ \\
\hline $\mathrm{NH}_{4}^{+} 0: 100 \mathrm{NO}_{3}^{-}$ & $6,05 \mathrm{a}$ & $2,17 \mathrm{a}$ & $44,8 \mathrm{c}$ \\
\hline CV (\%) & 7,54 & 12,3 & 17,0 \\
\hline
\end{tabular}

${ }^{(1)}$ Médias seguidas por letras iguais nas colunas não diferem entre si pelo teste do DMS ( $p>0,05)$.

visto que são absorvidos por transportadores do tipo canais, de baixa afinidade (LATS) ou menor seletividade, em concentrações na faixa milimolar (Britto \& Kronzucker, 2002). Assim, devido à similaridade de algumas propriedades físico-químicas, como carga e diâmetro do íon hidratado, $\mathrm{O}_{4}{ }^{+}$é capaz de ocupar

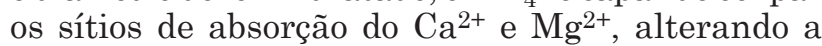
absorção desses cátions, e, consequentemente, causa a entrada de $\mathrm{NH}_{4}{ }^{+}$em quantidades superiores à capacidade de assimilação das raízes. A redução da absorção de $\mathrm{Ca}$ e $\mathrm{Mg}$ na presença de $\mathrm{NH}_{4}{ }^{+}$pode acarretar deficiência desses elementos e, assim, alterar o desenvolvimento normal da planta, conforme relatado por Wang et al. (1996) e Balkos et al. (2010).

$\mathrm{O}$ estudo indica que as plantas supridas com $\mathrm{NH}_{4}{ }^{+}$ e $\mathrm{NO}_{3}{ }^{-}$de forma combinada tiveram maior aproveitamento de N, K, Ca e Mg (Quadro 4). Isso mostra que, na proporção adequada de $\mathrm{NH}_{4}{ }^{+} \mathrm{e} \mathrm{NO}_{3}{ }^{-}$, o desenvolvimento das plantas é beneficiado, caracterizando maior eficiência no aproveitamento dos nutrientes fornecidos, em relação às plantas em que o $\mathrm{N}$ foi fornecido isoladamente na forma de $\mathrm{NH}_{4}{ }^{+} \mathrm{ou}$
$\mathrm{NO}_{3}{ }^{-}$. A importância de considerar a absorção total dos elementos possibilita concluir com maior segurança sobre o efeito dos tratamentos no desenvolvimento das plantas e na eficiência de absorção de nutrientes, ao contrário de se considerar somente a concentração do elemento no tecido. A dificuldade dessa interpretação está no fato de que a variação no crescimento da planta, juntamente com o armazenamento de nutrientes nos vacúolos das células, determinam a concentração e, ou, a diluição do nutriente no tecido, gerando dúvidas sobre a real utilização do elemento em nível metabólico.

$\mathrm{O}$ maior teor de $\mathrm{N}$ na parte aérea com o suprimento combinado, analisado juntamente com a intensidade dos sintomas de toxidez apresentados em cada tratamento, indica que a presença de $\mathrm{NO}_{3}{ }^{-}$é determinante para o desenvolvimento normal do arroz e que - em condições de cultivo em solo alagado, que propicia a elevação da concentração de $\mathrm{NH}_{4}{ }^{+}$- este possui algum mecanismo que reduza a quantidade de $\mathrm{NH}_{4}{ }^{+}$absorvida ou que a nitrificação na rizosfera é responsável por fornecer uma proporção de $\mathrm{NH}_{4}{ }^{+} \mathrm{e}$ $\mathrm{NO}_{3}{ }^{-}$adequada para promover o desenvolvimento normal da planta sem apresentar toxidez ao $\mathrm{NH}_{4}{ }^{+}$, conforme sugerem Kronzucker et al. (2000), Britto \& Kronzucker (2002), Guy \& Kirk (2003) e Duan et al. (2006, 2007).

\section{CONCLUSÕES}

1. O suprimento combinado de amônio e de nitrato proporciona maior produção de biomassa de arroz em relação às fontes supridas isoladamente, indicando que o nitrato também é uma fonte importante de $\mathrm{N}$ e que o balanço entre as fontes favorece o desenvolvimento do arroz irrigado.

2. A presença de amônio causa toxidez ao arroz irrigado até a proporção de $75 \%$ em relação ao nitrato em solução nutritiva com $5 \mathrm{mmol} \mathrm{L}^{-1}$ de $\mathrm{N}$, limitando a absorção de $\mathrm{Ca}$ e de $\mathrm{Mg}$ sem, porém, alterar a absorção de $\mathrm{N}$ e K.

3. A análise da seiva do xilema foi eficiente para indicar que o amônio afeta negativamente a absorção de $\mathrm{K}$, Ca e $\mathrm{Mg}$, com magnitude dependente da sua concentração no meio.

\section{LITERATURA CITADA}

ARMSTRONG, W. Radial oxygen losses from intact rice roots as affected by distance from the apex, respiration, and waterlogging. Physiol. Plant., 25:192-197, 1971.

BALKOS, K.D.; BRITTO, D.T. \& KRONZUCKER, H. Optimization of ammonium acquisition and metabolism by potassium in rice (Oryza sativa L. cv. IR-72). Plant Cell Environ., 33:23-34, 2010. 
BRIONES JR., A.M.; OKABE, S.; UMEMIYA, Y.; RAMSING, N.B.; REICHARDT W. \& OKUYAMA, H. Ammoniaoxidizing bacteria on root biofilms and their possible contribution to $\mathrm{N}$ use efficiency of different rice cultivars. Plant Soil, 250:335-348, 2003.

BRITTO, D.T. \& KRONZUCKER, H.J. Plant nitrogen transport and its regulation in changing soil environments. J. Crop Improvem., 15:1-23, 2005.

BRITTO, D.T. \& KRONZUCKER, H.J. $\mathrm{NH}_{4}{ }^{+}$toxicity in higher plants: A critical review. J. Plant Physiol., 159:567-584, 2002.

BRITTO, D.T.; SIDDIQI, M.Y.; GLASS, A.D.M. \& KRONZUCKER, H.J. Futile transmembrane $\mathrm{NH}_{4}{ }^{+}$ cycling: A cellular hypothesis to explain ammonium toxicity in plants. Proc. Nat. Acad. Sci., USA, 98:4255-4258, 2001.

CAO, Y.; FAN, X.R.; SUN, S.B.; XU, G.H.; HU, J. \& SHEN, Q.R. Effect of nitrate activities and transcript levels of nitrate reductase and glutamine synthetase in rice. Pedosphere, 18-664-673, 2008.

COLMER, T.D. Long-distance transport of gases in plants: A perspective on internal aeration and radial oxygen loss from roots. Plant Cell Environ., 26:17-36, 2003.

CORUZZI, G. \& BUSH, D.R. Nitrogen and carbon nutrient and metabolite signaling in plants. Plant Physiol., 125:6164, 2001.

COUNCE, P.A.; KEISLING, T.C. \& MITCHELL, A. A uniform, objective, and adaptive system for expressing rice development. Crop Sci., 40:436-443, 2000.

COX, W.J. \& REISENAUER, H.M. Growth and ion uptake by wheat supplied with nitrogen as nitrate, or ammonium, or both. Plant Soil, 38:363-380, 1973.

CRAWFORD, N.M. Nitrate: Nutrient and signal for plant growth. Plant Cell, 7:859-868, 1995.

DUAN, Y.H.; ZHANG, Y.L.; YE, L.T.; FAN, X.R.; XU, G.H. \& SHEN, Q.R. Responses of rice cultivars with different nitrogen use efficiency to partial nitrate nutrition. Ann. Bot., 99:1153-1160, 2007.

DUAN, Y.H.; ZHANG, Y.L.; SHEN, Q.R. \& WANG, S.W. Nitrate effect on rice growth and nitrogen absorption and assimilation at different growth stages. Pedosphere, 16:707-717, 2006.

EPSTEIN, E. \& BLOOM, A.J. Nutrição mineral de plantas: princípios e perspectivas. Londrina, Planta, 2006. 403p.

FORDE, B.G. Local and long-range signalling pathways regulating plant responses to nitrate. Ann. Rev. Plant Biol., 53:203-224, 2002.

GUY, J. \& KIRK, D. Rice root properties for internal aeration and efficient nutrient acquisition in submerged soils. New Phytol., 159:185-194, 2003.

HAYNES, R.J. \& GOH, K.M. Ammonium and nitrate nutrition of plants. Biol. Rev., 53:465-510, 1978.
HOWITT, S.M. \& UDVARDI, M.K. Structure, function and regulation of ammonium transportes in plants. Biochem. Biophys. Acta, 1465:152-170, 2000.

KIRK G.J.D. Plant-mediated processes to acquire nutrients: Nitrogen uptake by rice plants. Plant Soil, 232:129-134, 2001.

KIRK, G.J.D. \& KRONZUCKER, H.J. The potential for nitrification and nitrate uptake in the rhizosphere of wetland plants: A modeling study. Ann. Bot., 96:639-646, 2005 .

KRONZUCKER, H.J.; BRITTO, D.T.; DAVENPORT, R.J. \& TESTER M. Ammonium toxicity and the real cost of transport. Trends Plant Sci., 6:335-337, 2001.

KRONZUCKER, H.J.; GLASS, A.D.M.; SIDDIQI, M.Y. \& KIRK, G.J.D. Comparative kinetic analysis of ammonium and nitrate acquisition by tropical lowland rice: Implications for rice cultivation and yield potential. New Phytol., 145:471-476, 2000 .

KRONZUCKER, H.J.; SIDDIQI, M.Y.; GLASS, A.D.M. \& KIRK, G.J.D. Nitrate-ammonium synergism in rice. A subcellular flux analysis. Plant Physiol., 119:1041-1045, 1999.

LI, Y.L.; ZHANG, Y.L.; HU, J. \& SHEN, Q.R. Contribution of nitrification happened in rhizospheric soil growing with different rice cultivars to N nutrition. Biol. Fert. Soils, 43:417-425, 2006

MARSCHNER, H. Mineral nutrition of higher plants. 2.ed. London, Academic Press, 1995. 889p.

OAKS, A. A re-evaluation of nitrogen assimilation in roots. Bioscience, 42:103-111, 1992.

PONNAMPERUMA, F. N. The chemistry of submerged soils. Adv. Agron., 24:29-96, 1972.

QIAN, X.Q.; SHEN, Q.R.; XU, G.H.; WANG, J.J. \& ZHOU, M.Y. Nitrogen form effects on yield and nitrogen uptake of rice crop grown in aerobic soil. J. Plant Nut., 27:10611076, 2004.

REDDY, K.S. \& MENARY, R.C. nitrate reductase and nitrate accumulation in relation to nitrate toxicity in Boronia megastigma. Phisiol. Plant., 78:430-434, 1990.

SCHJOERRING, J.K.; HUSTED, S.; MACK, G. \& MATTSON, M. The regulation of ammonium translocation in plants. J. Exper. Bot., 53:883-890, 2002.

TAIZ, L. \& ZIEGER, E. Fisiologia vegetal. 3.ed. Porto Alegre, Artmed, 2008.705p.

TEDESCO, M.J.; GIANELLO, C.; BISSANI, C.A.; BOHNEN, H. \& VOLKWEISS, S.J. Análises de solo, planta e outros materiais. 2.ed. Porto Alegre, Universidade Federal do Rio Grande do Sul, 1995. 174p. (Boletim Técnico, 5)

WANG, M.Y.; SIDDIQI, M.Y. \& GLASS, A.D.M. Interactions between $\mathrm{K}^{+}$and $\mathrm{NH}_{4}^{+}$: Effects on ion uptake by rice roots. Plant Cell Environ., 19:1037-1046, 1996.

WANG, M.Y.; GLASS, A.D.M.; SHAFF, J.E. \& KOCHIAN, L.V. Ammonium uptake by rice roots. II. Electrophysiology. Plant Physiol., 104:899-906, 1994. 
WANG, M.Y.; SIDDIQI, M.Y.; RUTH, T.J. \& GLASS, A.D.M. Ammonium uptake by rice roots. I. Kinetics of ${ }^{13} \mathrm{NH}_{4}{ }^{+}$ influx across the plasmalemma. Plant Physiol., 103:12591267,1993

WILLIAMS, L.E. \& MILLER, A.J. Transporters responsible for the uptake and partitioning of nitrogenous solutes. Ann. Rev. Plant Physiol. Plant Molec. Biol., 52:659-688, 2001.
WOLT, J.D. Soil solution chemistry. New York, John Wiley \& Sons, 1994.

YONEYAMA, T. \& KUMUZAWUA, K. Kinetic study of the assimilation of $15 \mathrm{~N}$-labeled nitrate in rice seedlings. Plant Cell Physiol., 16:21-26, 1975. 